\title{
Innovations in healthcare delivery and policy: Implications for the role of the psychologist in preventing and treating diabetes
}

\author{
Suzanne Bennett Johnson \\ Department of Behavioral Science and Social Medicine, Florida State University College of Medicine
}

\section{David Marrero}

Department of Medicine, Indiana University School of Medicine

The biomedical model has dominated Western medicine for over 100 years; it underlies U.S. medical education, research, and health care delivery. Although it has enjoyed much success, particularly in the areas of increased life expectancy and control of infectious episodes, its limitations have become more and more apparent. In this article, we review the limitations of the biomedical model for addressing current U.S. health care challenges — chronic disease and its escalating costs, with a particular focus on the rising diabetes epidemic, both in the United States and worldwide. We review new models of care designed to better address our current health care challenges and then place the Patient Protection and Affordable Care Act (ACA, 2010) within this context. Finally, we articulate the opportunities these new models offer psychologists who wish to play a larger role in the prevention and treatment of diabetes. Despite their conceptual appeal, proponents of these new models often face considerable challenges garnering widespread acceptance by organizations and individuals steeped in traditional health care based on the biomedical model. Like other health care providers, psychologists need to move away from the mind-body dualism underlying the biomedical model and embrace the integrated care opportunities that characterize current innovations in U.S. health care delivery (Johnson, 2013).

\section{Limitations of the Biomedical Model for Addressing Current U.S. Health Care Challenges}

This is the author's manuscript of the article published in final edited form as:

Johnson, S. B., \& Marrero, D. (2016). Innovations in healthcare delivery and policy: Implications for the role of the psychologist in preventing and treating diabetes. American Psychologist, 71(7), 628-637. https://doi.org/10.1037/a0040439 
The biomedical model focuses on biologic factors of health and illness to the exclusion of psychological and social factors (Stedman’s Medical Dictionary, 2006). The model is both exclusionary and reductionistic, leading to a narrow focus on identifying the underlying physiological cause of disease and to mind-body dualism in which biologic processes are considered separate from—and far more important than—psychological, behavioral, or social processes (Engel, 1977; Russell, 2013). The model had early roots in Descartes' conceptualization of the body as part of the physical world and the mind as part of the spiritual world. But it was during the 19th century that the model gained widespread acceptance, with the discovery of germs and their impact on the body and medicine's adoption of a more scientific approach to health and illness (Russell, 2013). For more than 100 years, the biomedical model has profoundly affected U.S. health care training, delivery, and research. Those who treat the body (e.g., physicians) are trained separately from those who treat the mind (e.g., psychologists). U.S. health care has evolved into a fee-for-service system that pays for biomedical procedures, resulting in escalating health care costs associated with ever-increasing diagnostic tests in the search for the biologic or physical disorder underlying the patient's symptoms or biomedical treatments in response to patient complaints.

U.S. health care based on the biomedical model is not only expensive-it does not adequately address today's health care challenges; U.S. health care is the most expensive in the world, and U.S. life expectancy remains lower than most other developed countries (O’Rourke \& Iammarino, 2002). Although the biomedical model successfully addresses infectious illness, it has proved inadequate for meeting today's primary public health challenge: chronic disease. Nearly half of all U.S. adults have a chronic illness, seven in 10 deaths are a result of chronic disease, and 75\% of U.S. health care costs are directed at chronic illness (American Diabetes Association, 2013; Centers for Disease Control and Prevention, 2009). Human behaviors—such as smoking, obesity resulting from poor diet and lack of exercise, and substance abuse-play a major role in the development, course, and outcomes of many chronic diseases, including diabetes. Estimates from the Centers for Disease Control and Prevention indicate that 50\% of health outcomes in the United States can be attributed to such behaviors (Amara et al., 2003). The 
biomedical model, with its focus on biology and physiology, and the exclusion of behavior, is insufficient to address the critical role behavior plays in both the etiology of chronic disease and its management. Instead, it seeks to alleviate the consequences of chronic disease through more and more diagnostic tests and biomedical interventions. Disease prevention through improving people's lifestyle behaviors is generally ignored in favor of biomedical tests and treatments once the chronic disease is well established. This is particularly evident when considering Type 2 diabetes (T2D), a chronic disease characterized by the body's inability to effectively metabolize food, resulting in elevated blood glucose. Affecting 29 million Americans, diabetes is the seventh leading cause of death and the leading cause of blindness, kidney failure, and lower extremity amputations (Amos, McCarty, \& Zimmet, 1997; Centers for Disease Control and Prevention, 2014; Miniño \& Murphy, 2012). Of particular concern are the 86 million persons in the United States who have prediabetes, a condition that significantly increases their risk for developing T2D (Centers for Disease Control and Prevention, 2014; Tabák, Herder, Rathmann, Brunner, \& Kivimäki, 2012). This number, which is rapidly growing, is largely attributed to behavioral factors, notably the growing epidemic of obesity (Ogden, Carroll, Kit, \& Flegal, 2014). To date, even though research has clearly established that there are effective behavioral interventions that can significantly reduce this risk (Goldberg, 2006; Knowler et al., 2002), the health care system has been extremely slow to adopt or utilize behavioral approaches (Ruterbusch, 2014; Tabák et al., 2012), and the incidence and prevalence of diabetes continues to grow. In addition, large health disparities exist in both the prevalence and outcomes of diabetes in the United States, particularly across socioeconomic classes (National Center for Health Statistics, 2012). These disparities are not adequately addressed by the biomedical model because of its exclusion of behavior and social context.

\section{Failure of the Biomedical Model to Address the U.S. Diabetes Epidemic}

Although the incidence and prevalence of diabetes did not change significantly in the 1980s, the United States experienced a rapid increase beginning in 1990 when approximately 3.5\% of the U.S. population had diagnosed diabetes (Geiss et al., 2014); today nearly 7\% of the population has diagnosed 
diabetes and another $2 \%$ of the population has the disease but remains undiagnosed, for a total of more than 29 million people (Centers for Disease Control and Prevention, 2014). The lifetime risk of T2D has skyrocketed; 33\% of boys and 39\% of girls born in 2000 are expected to develop T2D in their lifetime (Narayan, Boyle, Thompson, Sorensen, \& Williamson, 2003). The lifetime risk is highest for ethnic minorities; half of Black and Hispanic girls born in 2000 are expected to develop T2D in their lifetime (Narayan et al., 2003). The cost of this epidemic is enormous; annual health care costs for people with diabetes are more than double the costs of people without diabetes. In 2007, 20\% of U.S. health care dollars was spent on people with diabetes (American Diabetes Association, 2008). In 2012, the annual expenditure for diabetes was estimated at \$245 billion (Centers for Disease Control and Prevention, 2014). These costs will only escalate as more and more Americans develop the disease.

Several factors underlie the U.S. diabetes epidemic, including longer life expectancy and the increasing proportion of the U.S. population represented by ethnic minorities. However, the primary driver has been the rapid increase in obesity—a major risk factor for diabetes. Currently, 35\% of U.S. adults and $17 \%$ of children are obese. Ethnic minority women are particularly affected: 57\% of African American women and 44\% of Hispanic women are obese (Ogden et al., 2014). Obesity is associated with a dramatically higher lifetime risk of T2D. Between $60 \%$ to $80 \%$ of obese African American and Hispanic women are expected to develop T2D in their lifetime (Narayan, Boyle, Thompson, Gregg, \& Williamson, 2007). Although the biomedical model has been useful in developing diagnostic tests (including tests that identify individuals with prediabetes) and treatments for the numerous complications associated with diabetes (e.g., heart disease, kidney disease, retinopathy, neuropathy), its failure to attend to behavioral factors so important to the development of the disease (obesity and sedentary behavior) and its management (nonadherence and inadequate self-management) have resulted in ever-increasing health care costs, with few resources devoted to diabetes prevention.

\section{New Models of Care: Chronic Care, Social Ecological, Patient Empowerment, and Patient- Centered Medical Homes}


In a 1977 article in Science, George Engel was one of the first to point out the serious limitations of the biomedical model. He argued the model was inadequate because it excluded the social, psychological, and behavioral dimensions of illness. He proposed the biopsychosocial model in which biology remained important, but the patient's psychological, behavioral, and social contexts were given equal importance. Since that time, it has become increasingly clear that the complex chronic diseases we now face, including diabetes, cannot be understood and managed adequately from a single discipline biomedical perspective. Rather, diabetes — and other chronic diseases — must be approached from a multilevel, multidisciplinary, systems-oriented perspective that is attuned to the diverse origins and underlying dynamics of chronic disease. A number of models have been proposed that would move the U.S. health care system away from the biomedical model toward a the kind of comprehensive and inclusive model needed to adequately care for patients with diabetes.

The chronic care model views the patient within a larger community and health care context. The six pillars of this model include: (a) self-management support in which the patient is viewed as an active member of the care team who has acquired the skills and confidence to manage his or her own disease; (b) a health care team that focuses on the chronic nature of the disease and assists the patient to successfully self-manage the disease; (c) decision-support systems that assure that evidence-based practice guidelines are integrated into the daily practice of the health care team; (d) computerized information systems that serve as reminder systems to promote healthcare team compliance with practice guidelines, provide feedback to providers on how well patients are doing, and produce registries to assist in planning patient and population-based care; (e) a health care system—including purchasers and insurers - that rewards the quality of care delivered; and (f) community linkages to improve disease prevention as well as support patient self-management (Bodenheimer, Wagner, \& Grumbach, 2002a). Available evidence suggests that this approach can improve patient care for people with diabetes as well as other chronic diseases, leading to better health outcomes, often at reduced cost (Bodenheimer, Wagner, \& Grumbach, 2002b; Coleman, Austin, Brach, \& Wagner, 2009). 
The social ecological model also places the individual in a larger health care and community context (Fisher et al., 2002; Sallis, Owen, \& Fisher, 2008; Stokols, 1992). The model had its origins in biology, but evolved into a general framework for understanding people’s relationships with their physical and sociocultural surroundings. The model—shown in Figure 1 -postulates that the individual operates within the context of family, friends, and small groups, which are, in turn, embedded within several layers of larger communities and systems (Bronfenbrenner, 1977, 1999).

The model views the individual as a whole person, a unique composite of biological, emotional, cognitive, social, and behavioral characteristics. For example, people with diabetes suffer from clinical depression at significantly higher rates than people not afflicted with the disease (R. J. Anderson, Freedland, Clouse, \& Lustman, 2001; de Groot, Anderson, Freedland, Clouse, \& Lustman, 2001; de Groot, Golden, \& Wagner, 2016). Depression can severely impact medication-taking adherence and diabetes self-management (DiMatteo, Lepper, \& Croghan, 2000; Gonzalez et al., 2007; Gonzalez, Tanenbaum, \& Commissariat, 2016; Lin et al., 2004). Consequently, the model would promote an intervention that addressed the individual's diabetes care behaviors within the context of the patient's depression.

The social ecological model also highlights the important role significant others play in patients' ability to integrate recommended therapy into their lives. For example, if the individual is placed on a specific diet, yet the family does not support this dietary approach, the family's attitudes and behaviors can prove to be insurmountable barriers to reducing weight. Similarly, friends or coworkers may promote ostensibly normal social behavior (e.g., social eating and drinking) that is health jeopardizing to the person with diabetes (Wiebe, Helgeson, \& Berg, 2016).

The model also focuses on how the larger community in which a person lives can influence patient behavior. We live in an obesogenic environment that makes access to hypercaloric foods both easy and cheap (Kirk, Penney, \& McHugh, 2010). For many people, economic stress can lead to using fast food as a primary food source to meet nutritional needs. This is especially the case in low-income urban 
settings that are often characterized as “food deserts," places devoid of sources for fresh produce and healthier food choices (Blanchard \& Matthews, 2007).

Of course, the health care system itself is a critical component of the social ecological model. The current system often emphasizes biomedical tests and interventions, providing few or no resources for diabetes prevention or diabetes self-management.

The model suggests that diabetes can best be addressed by focusing on the individual within a relationship, community, and societal context. When considering interventions, the number of ecological levels addressed may be important to intervention effectiveness. For example, successful interventions that increase community opportunities for exercise and access to healthy food, coupled with programs encouraging individuals and families to participate in wellness programs, may be more effective than weight loss programs aimed solely at obese individuals. By utilizing the broader range of community resources to promote programs for reducing diabetes risk, a greater number of individuals may be reached with greater impact (Grzywacz \& Fuqua, 2000; Stokols, 1996).

Both the chronic care and social ecological models emphasize the active role of the patient. The patient empowerment model focuses specifically on this critical aspect of health care. The patient empowerment model was specifically developed for the care of patents with T2D, but is applicable to other chronic diseases as well. The model highlights the importance of shared decision making in which the health care provider actively solicits the patient's input in therapeutic decisions; it places the patient, rather than the physician, in the center of the therapeutic decision-making process (R. Anderson et al., 2000; R. M. Anderson, 1995). The model is characterized by four basic principles: (a) the majority of chronic disease care is provided by the patient, and therefore the patient is the locus of control and decision making in the daily treatment of the disease; (b) the primary mission of the health care team is to provide ongoing expertise, education, and psychosocial support so that patients can make informed decisions about their daily care; (c) people are much more likely to make and maintain behavior changes if those changes are personally meaningful and freely chosen; and (d) all people, regardless of their 
situation, have the capacity to make choices that can make a difference in the quality of their lives (R. Anderson et al., 2000; Funnell \& Anderson, 2004). The model encourages a semistructured approach to helping patients initiate behavior change. The focus is to ask questions that help patients identify and commit to a behavior change plan to improve their ability to live with and care for their disease.

Questions are designed to help patients (a) discover the issues of importance to them, (b) explore their feelings about these issues, (c) generate possible approaches to addressing these issues, (d) commit to changing their situation and their perception of self-efficacy, (e) identify possible action steps, and (f) initiate their action plan (Funnell \& Anderson, 2004). These concepts mirror the foundations of many psychological therapy systems, such as the transtheoretical model of stages of change (Prochaska \& Velicer, 1997).

The growing awareness of the vital role that patient psychosocial factors play in achieving therapeutic goals led to the incorporation of the patient empowerment model into the concept of the Patient-Centered Medical Home. In 2007, the major primary care physician associations developed and endorsed the Joint Principles of the Patient-Centered Medical Home (American Academy of Family Physicians, American Academy of Pediatrics, American College of Physicians, \& American Osteopathic Association, 2007). The model describes how primary care should be organized and delivered throughout the health care system using a patient-centered approach that is team-based, coordinated, and focused on quality and safety. In 2014, the model was expanded to include behavioral health care as a central component of the Joint Principles (Working Party Group on Integrated Behavioral Healthcare, 2014). This expansion was endorsed—with commentary—by the American Psychological Association (N. B. Anderson et al., 2014).

\section{The Patient Protection and Affordable Care Act}

ACA is consistent with many of the tenets of these new models of health care. For example, the law requires that essential health benefits not be limited to biomedical concerns but must include mental 
health, preventive, and wellness services, and chronic disease management-aspects of health care that had previously been “carved out” or completely ignored.

Further, the law stipulates that U.S. Preventive Services Task Force Grade A (high certainty that the net benefit is substantial) and B (high certainty that the net benefit is moderate or there is moderate certainty that the net benefit is moderate to substantial) recommendations must be provided. U.S. Preventive Services Task Force (2014) recommendations are graded based on the available scientific literature. Many Grade A and B recommendations are behavioral, and several are directly relevant to the prevention or management of patients with diabetes (obesity screening and counseling; healthy diet and physical activity counseling, depression screening, tobacco use counseling, and intervention; alcohol misuse screening and counseling).

The law also promotes the concept of patient-centered team-based integrated care through the Agency for Health Care Research and Quality’s emphasis on the Patient Centered Medical Home. In addition to biomedical indices, ACA highlights patient functioning and quality of life as important health outcomes, establishing the Patient-Centered Outcomes Research Institute, which "helps people and their caregivers communicate and make informed healthcare decisions, allowing their voices to be heard in assessing the value of healthcare options.”

It is important to note that ACA focuses on provider behavior as well as patient behavior. In addition to requiring evidence-based screening and interventions as part of the essential benefits, ACA emphasizes patient safety and the reduction of medical errors. The electronic health record, including decision-support systems, is often viewed as a mechanism to enhance patient safety and reduce medical errors via improved health care data storage, access and sharing, enhanced communication between providers, and greater provider adherence to evidence-based standards of care.

Many members of the health care community have responded positively to ACA and the new models of health care it embraces. For example, the Association of American Medical Colleges, the 
American Association of Colleges of Nursing, the American Association of Colleges of Pharmacy, the American Association of Colleges of Osteopathic Medicine, the American Dental Association, and the Association of the Schools of Public Health came together to define what is meant by team-based interprofessional practice (Interprofessional Education Collaborative Expert Panel, 2011). Although not a participant in the development of this document, the American Psychological Association has officially endorsed it (Kelly, 2014).

Diabetes care has often been aligned with the concept of the patient-centered care promoted by the ACA, with numerous demonstration projects exhibiting positive results in terms of health outcomes, patient satisfaction, and reduced costs (Bojadzievski \& Gabbay, 2011). The American Diabetes Association has long advocated for psychological and behavioral assessment and intervention as part of its standards of care. For example, current standards include recommendations for diabetes selfmanagement and support, nutrition, weight loss, physical activity, smoking cessation, and psychosocial assessment and care. Psychosocial assessment and care recommendations specifically include ongoing assessment of the patient's psychological and social functioning as part of standard care, with treatment and referral to a mental health specialist when indicated (American Diabetes Association, 2015). In 2012, the American Diabetes Association published an authoritative text, Psychosocial Care for People with Diabetes (Young-Hyman \& Peyrot, 2012).

\section{Psychologists in Integrated Patient-Centered Care for People With Diabetes: Opportunities and \\ Challenges}

There are numerous opportunities for psychologists to serve in integrated patient-centered care for people with diabetes. In addition to the traditional role as a referral resource for those patients in need of extensive psychological services, there are many other roles appropriate for psychologists interested in participating in these newer models of care. Integrated care requires that both the mental and physical health needs of the patient with diabetes are met. Consequently, integrated care teams are critically in need of expertise in the selection of psychological assessment and screening tools, in the delivery of 
evidence-based brief interventions, and the promotion of effective interdisciplinary team functioning. Diabetes care teams need mental health expertise to assist patients in selecting therapeutic goals, enhance patient-provider communication, improve diabetes self-management, address needed lifestyle changes for both patient and family, and attend to possible depression, chronic pain, or other forms of distress. Many patients face the emotional, interpersonal, and functional sequelae of the serious complications associated with diabetes_-blindness, lower extremity amputations, chronic neurologic pain, kidney failure requiring dialysis or transplantation, and impotence. Psychologists are fortunate that the need for behavioral and psychological services is clearly articulated in the American Diabetes Association's (2015) standards of care.

Prevention plays a more central role in the newer models of care. More than 86 million Americans have prediabetes (Centers for Disease Control and Prevention, 2014), a condition usually associated with excess body weight that places the person at great risk for developing T2D (Pi-Sunyer et al., 2007). Fortunately, there is strong science demonstrating that the risk for developing T2D in persons with prediabetes can be significantly reduced by behavioral interventions designed to achieve modest weight loss and increased physical activity (Goldberg, 2006; Knowler et al., 2002; Venditti, 2016). The Center for Disease Control has used these important findings to develop the National Diabetes Prevention Program (http://www.cdc.gov/diabetes/prevention/). Unfortunately, most physicians are not trained in the techniques needed to effectively implement the necessary intensive behavioral interventions required for T2D prevention and treatment, highlighting the need for such expertise on the health care team. Indeed, considerable literature has shown that for weight loss programs to be effective, they need to address the psychological and social factors that influence eating and physical activity patterns (Friedman \& Brownell, 1995; Stice, 2002).

Opportunities for psychologists interested in these new models of health care are certainly not limited to direct patient care. Expertise is needed to conduct research to assure the highest level of patientcentered evidence-based care, to guide clinic and health system policy decisions, and to select appropriate 
outcome measures that adequately address functioning and quality of life from the patient's point of view. In addition, work with communities is essential for both diabetes prevention and optimal selfmanagement for those with the disease.

Despite these numerous and exciting opportunities, there are important challenges to full inclusion of psychologists in patient-centered integrated care for patients with diabetes. These challenges are both external and internal to psychology.

External challenges include the long history patients, physicians, and health care systems have with the traditional biomedical model. Most physicians have not been trained to attend to or deal with patients’ psychological concerns or patients’ difficulty managing diabetes on a daily basis. Many physicians have little or no experience working on interdisciplinary health care teams. Thus, many physicians may be unwilling or unable to elicit and explore the emotional content of a diabetes problem that a patient has identified. In addition, many remain burdened by the legacy of the biomedical model in which the expectation is to solve problems for patients rather than with them (Thielke, Vannoy, \& Unutzer, 2007).

Many medical professionals and health system administrators are unaware of what psychologists have to offer. They may discount the legitimacy of psychological science and see psychological services as "common sense" or something anyone can do. Consequently, they may believe that such services can be delivered at low cost by persons with little training. Having been trained to view themselves as the ultimate medical authority, many physicians may view other health care team members as "physicianextenders” rather than equal partners in collaborative care (Leipzig et al., 2002). This problem is exacerbated by the fact that although ACA requires that behavioral and mental health services be provided, it does not specify who will deliver these services and leaves the details of the essential benefits to the states (Bagley \& Levy, 2014). 
Patients, too, may experience difficulty acknowledging their psychological concerns or seeing the physician as anything other than the ultimate authority. Many patients may express fear, anxiety, or discomfort in response to provider efforts to engage them in shared decision making or discussion of their diabetes self-care (Rodriguez-Osorio \& Dominguez-Cherit, 2008). Some patients may resist psychological services, even when offered by a member of an interdisciplinary health care team, in response to the stigma such services have acquired in the context of traditional biomedical care (Thielke et al., 2007).

Certainly, one of the most important external challenges to high-quality patient-centered integrated care is the current system's fee for service model that rewards providers for volume of services instead of quality of care. It is clear that payment models must change if these newer models of health care are to become a permanent reality (Kathol, Butler, McAlpine, \& Kane, 2010; O’Donnell, Williams, \& Kilbourne, 2013). Since the U.S. health care system is not a single-payer system, changing the payment model is a major challenge because so many payers are involved. For example, the Medicare Payment Advisory Commission (MedPAC) has endorsed bundled payments as an alternative to fee for service payments; a set fee for managing a patient with diabetes for a calendar year would be established, essentially providing a "bundled payment” for all the services of the health care team. Other approaches include pay-for-performance or gain-sharing arrangements that are designed to reward providers for efficiently delivering appropriate care (Korda \& Eldridge, 2011). Often, a payment system is devised that rewards care coordination and quality in addition to traditional fee for service (Bojadzievski \& Gabbay, 2011).

The situation is further complicated by our current fee-for-service system. Many years ago, the Center for Medicare and Medicaid Services (CMS) entered into an agreement with the American Medical Association to make recommendations as to what procedures should be paid for and how much Medicare should pay for each procedure. Although CMS is not required to accept these recommendations, it does so almost all of the time because it has no alternative resources for making such determinations. The impact 
goes well beyond Medicare because most private insurance companies follow CMS determinations. The system has been strongly criticized as secretive, a conflict of interest because it is physician and specialty driven and generates the vast majority of the American Medical Association's revenue, and unfairly favoring specialty practice over primary care (Eaton, 2010; Edwards, 2013). In fact, MedPAC—which prepares a report to the U.S. Congress annually about issues affecting the Medicare program—has repeatedly argued for a change in this fee-for-service system and greater equity in payments between primary care and other specialties (MedPAC, 2014). To date, psychology has played a relatively minor role in these activities, making it difficult to assure that psychological services as part of patient-centered integrated care can be appropriately reimbursed. For example, CMS has approved reimbursement for intensive behavioral counseling and behavioral therapy for weight loss, but limited this only to "primary care” providers, which it defines as a primary care physician, a clinical nurse specialist, a nurse practitioner, or a physician assistant; psychologists were explicitly excluded, despite the fact that psychological science provided the research in support of this recommendation and both the American Psychological Association and the Society of Behavioral Medicine opposed CMS’s exclusion of psychologists (Pagoto, Pbert, Emmons, \& Society of Behavioral Medicine Public Policy Leadership Group, 2012).

In addition to these external challenges, there are a number of internal challenges central to psychology’s practice and training models that may interfere with psychology’s integration into these newer models of health care. Psychology's practice and training models have been heavily influenced by the mind-body dualism of the biomedical model, training most psychologists as mental health providers who provide services in solo practices or in groups of other psychologists. Many psychologists see themselves as mental health providers rather than health providers, and may not have the skills needed to address the many concerns of patients with diabetes, including diabetes self-management, lifestyle behavior change, pain management, functional limitations, and imminent death. They are often unfamiliar with comorbid psychological conditions common in patients with diabetes as well as the best 
interventions to address such comorbidities. Most have no experience working on interdisciplinary teams and are unfamiliar with the larger health care culture, including evidence-based practice, treatment guidelines, and electronic health records. Many operate within the independent practice referral model with its 50-min therapeutic hour and have little experience with brief interventions delivered as part of an integrated care team. For all of these reasons, most psychologists have an identity as a mental health provider and do not see themselves as an important participant in the larger health care delivery system (American Psychological Association Board of Educational Affairs, 2011). They often struggle with identity issues vis-à-vis other mental health professionals rather than embracing the many opportunities for psychology in integrated patient-centered care. Perhaps most serious is the fact that psychology's current training programs are not producing sufficient numbers of psychologists trained in patientcentered integrated care to meet the need (Weil, 2015).

Fortunately, considerable resources are available for psychologists who want to immerse themselves in these new health delivery models. For example, the Council of Clinical Health Psychology Training Programs provides important resources for those interested in expanding their clinical health psychology skills at both the graduate and postgraduate level (http://cchptp.org/), APA’s Division 54 provides resources for training in pediatric psychology (http://www.apadivisions.org/division54/leadership/students/training/index.aspx), and APA's Division 22 provides resources for training in rehabilitation psychology (http://www.apadivisions.org/division-22/membership/training-sites.aspx). To focus specifically on opportunities for psychology in primary care, APA brought together nine organizations to identify the competencies for psychology practice in primary care (McDaniel et al., 2014), and APA devoted the entire August 2014 issue of the American Psychologist to this topic (McDaniel \& DeGruy, 2014). The present issue of the American Psychologist is another example of informing psychologists of the important and diverse roles open to psychologists in the care of people with diabetes. As mentioned previously, the American Diabetes Association annually publishes standards for the psychological care of patients with diabetes (American Diabetes Association, 2015) as well as 
more detailed texts on the subject (e.g., Young-Hyman \& Peyrot, 2012), devotes a section of its flagship journal Diabetes Care to psychological research, and has an Interest group, Behavioral Medicine and Psychology, as part of its organizational structure that assures relevant programming and continuing education at its annual convention (http://professional.diabetes.org/ResourcesForProfessionals.aspx?cid=71423).

\section{Conclusions and Future Directions}

This is an exciting and pivotal time in U.S. health care that has the potential to revolutionize not only how many Americans receive health care, but the quality of care they receive. There are great opportunities for psychologists to lend their considerable expertise to these newer models of patientcentered integrated care for patients with diabetes. However, for the role of psychologists to be fully realized, numerous external and internal challenges must be addressed. Psychologists and psychology training programs need to embrace psychology's role in the larger health care system and abandon mindbody dualism and a narrow identity as a mental health professional. Psychologists need to be trained to work with other health professionals on interdisciplinary teams, serving in an expanded role by helping patients with diabetes to manage their disease more effectively. Psychologists also need to be trained in the many mental health comorbidities associated with diabetes and how to address them.

If these newer models of health care are to replace the traditional biomedical approach that has long characterized the care of patients with diabetes, psychologists will need to band together with other like-minded health professionals to address the many barriers—including reimbursement challenges_that stand in the way. This means that psychologists must become more interdisciplinary, more familiar with the larger health care culture, more willing to expand their skill sets to address the concerns and needs of patients with diabetes, and more collaborative with other diabetes care providers both from a patient-care and a larger advocacy perspective. 


\section{Footnotes}

1 See https://pcmh.ahrq.gov/page/defining-pcmh.

2 See http://www.pcori.org/research-results/patient-centered-outcomes-research.

3 See https://www.cms.gov/medicare-coverage-database/details/nca-decision-

memo.aspx?\&NcaName=Intensive\%20Behavioral\%20Therapy\%20for\%20Obesity\&bc=ACAAAAAAIA AA\&NCAId $=253 \&$.

4 See https://www.cms.gov/medicare-coverage-database/staticpages/publiccomment.aspx?commentID=23506\&ReportType=nca. 


\section{References}

Amara, R., Bodenhorn, K., Cain, M., Carlson, R., Chambers, J., Cypress, D., . . Yu, K. (2003). Health and health care 2010: The forecast, the challenge (2nd ed.). San Francisco, CA: Jossey-Bass.

American Academy of Family Physicians, American Academy of Pediatrics, American College of Physicians, \& American Osteopathic Association. (2007, March). Joint principles of the patient-centered medical home. Retrieved from [http://www.idahopca.org/files/images/Joint_Priniciples_of_PCMH.pdf] American Diabetes Association. (2008). Economic costs of diabetes in the U.S. in 2007. Diabetes Care, 31, 596-615. 10.2337/dc08-9017

American Diabetes Association. (2013). Economic costs of diabetes in the U.S. in 2012. Diabetes Care, 36, 1033-1046. 10.2337/dc12-2625

American Diabetes Association. (2015). (4) Foundations of care: Education, nutrition, physical activity, smoking cessation, psychosocial care, and immunization. Diabetes Care, 38(Suppl. 1), S20-S30. 10.2337/dc15-S007

American Psychological Association Board of Educational Affairs. (2011). Report of the Primary Care Training Task Force to the APA Board of Educational Affairs. Retrieved from http://www.apa.org/ed/graduate/task-force-report.pdf

Amos, A. F., McCarty, D. J., \& Zimmet, P. (1997). The rising global burden of diabetes and its complications: Estimates and projections to the year 2010. Diabetic Medicine, 14(Suppl. 5), S7-S85. 10.1002/(SICI)1096-9136(199712)14:5+<S7::AID-DIA522>3.3.CO;2-I

Anderson, N. B., Belar, C. D., Cubic, B. A., Garrison, E. G., Johnson, S. B., \& Kaslow, N. J. (2014). Statement of the American Psychological Association in response to the "Joint Principles: Integrating behavioral health care into the patient-centered medical home.”Families, Systems, \& Health, 32, 141142. $10.1037 /$ fsh0000051 
Anderson, R., Funnell, M., Carlson, A., Saleh-Statin, N., Cradock, S., \& Skinner, T. C. (2000).

Facilitating self-care through empowerment. Psychology in Diabetes Care, 69-97.

Anderson, R. J., Freedland, K. E., Clouse, R. E., \& Lustman, P. J. (2001). The prevalence of comorbid depression in adults with diabetes: A meta-analysis. Diabetes Care, 24, 1069-1078.

10.2337/diacare.24.6.1069

Anderson, R. M. (1995). Patient empowerment and the traditional medical model. A case of irreconcilable differences?Diabetes Care, 18, 412-415. 10.2337/diacare.18.3.412

Bagley, N., \& Levy, H. (2014). Essential health benefits and the Affordable Care Act: Law and process. Journal of Health Politics, Policy and Law, 39, 441-465. 10.1215/03616878-2416325

Blanchard, T. C., \& Matthews, T. L. (2007). Retail concentration, food deserts, and food-disadvantaged communities in rural America. In C.Hinrichs \& T.Lyson (Eds.), Remaking the North American food system: Strategies for sustainability (pp. 201-215). Lincoln, NE: University of Nebraska Press. Retrieved from http://wtf.tw/ref/hinrichs_lyson.pdf

Bodenheimer, T., Wagner, E. H., \& Grumbach, K. (2002a). Improving primary care for patients with chronic illness. Journal of the American Medical Association, 288, 1775-1779.

10.1001/jama.288.14.1775

Bodenheimer, T., Wagner, E. H., \& Grumbach, K. (2002b). Improving primary care for patients with chronic illness: The chronic care model, Pt. 2. Journal of the American Medical Association, 288, 19091914. 10.1001/jama.288.15.1909

Bojadzievski, T., \& Gabbay, R. A. (2011). Patient-centered medical home and diabetes. Diabetes Care, 34, 1047-1053. 10.2337/dc10-1671

Bronfenbrenner, U. (1977). Toward an experimental ecology of human development. American Psychologist, 32, 513-531. 10.1037/0003-066X.32.7.513 
Bronfenbrenner, U. (1999). Environments in developmental perspective: Theoretical and operational models. In S.Friedman \& T.Wachs (Eds.), Measuring environment across the life span: Emerging methods and concepts (pp. 3-28). Washington DC: APA Press.

Centers for Disease Control and Prevention. (2009). The Power of prevention: Chronic disease . . . the public health challenge of the 21st century. Atlanta, GA: U. S. Department of Health and Human Services. Retrieved from http://www.cdc.gov/chronicdisease/pdf/2009-power-of-prevention.pdf Centers for Disease Control and Prevention. (2014). National diabetes statistics report: Estimates of diabetes and its burden in the United States, 2014. Atlanta, GA: U. S. Department of Health and Human Services. Retrieved from http://www.cdc.gov/diabetes/pubs/statsreport14/national-diabetes-reportweb.pdf

Coleman, K., Austin, B. T., Brach, C., \& Wagner, E. H. (2009). Evidence on the chronic care model in the new millennium. Health Affairs, 28, 75-85. 10.1377/hlthaff.28.1.75

de Groot, M., Anderson, R., Freedland, K. E., Clouse, R. E., \& Lustman, P. J. (2001). Association of depression and diabetes complications: A meta-analysis. Psychosomatic Medicine, 63, 619-630. 10.1097/00006842-200107000-00015

de Groot, M., Golden, S. H., \& Wagner, J. (2016). Psychological conditions in adults with diabetes. American Psychologist, 71, 552-562. 10.1037/a0040408

DiMatteo, M. R., Lepper, H. S., \& Croghan, T. W. (2000). Depression is a risk factor for noncompliance with medical treatment: Meta-analysis of the effects of anxiety and depression on patient adherence. Archives of Internal Medicine, 160, 2101-2107. 10.1001/archinte.160.14.2101

Eaton, J. (2010). Little-known American Medical Association group has outsized influence on Medicare payments: Healthful advice or conflict of interest? The Center for Public Integrity. Retrieved from 
http://www.publicintegrity.org/2010/11/07/2333/little-known-ama-group-has-outsized-influencemedicare-payments

Edwards, H. (2013, July-August). Special deal: The shadowy cartel of doctors that controls Medicare. Washingtonian Monthly Magazine. Retrieved from http://www.washingtonmonthly.com/magazine/july_august_2013/features/special_deal045641.php Engel, G. L. (1977). The need for a new medical model: A challenge for biomedicine. Science, 196, 129136. $10.1126 /$ science. 847460

Fisher, E. B., Walker, E. A., Bostrom, A., Fischhoff, B., Haire-Joshu, D., \& Johnson, S. B. (2002). Behavioral science research in the prevention of diabetes: Status and opportunities. Diabetes Care, 25, 599-606. 10.2337/diacare.25.3.599

Friedman, M. A., \& Brownell, K. D. (1995). Psychological correlates of obesity: Moving to the next research generation. Psychological Bulletin, 117, 3-20. 10.1037/0033-2909.117.1.3

Funnell, M. M., \& Anderson, R. M. (2004). Empowerment and self-management of diabetes. Clinical Diabetes, 22, 123-127. 10.2337/diaclin.22.3.123

Geiss, L. S., Wang, J., Cheng, Y. J., Thompson, T. J., Barker, L., Li, Y., . . Gregg, E. W. (2014). Prevalence and incidence trends for diagnosed diabetes among adults aged 20 to 79 years, United States, 1980-2012. Journal of the American Medical Association, 312, 1218-1226. 10.1001/jama.2014.11494

Goldberg, R. B. (2006). Lifestyle interventions to prevent type 2 diabetes. Lancet, 368, 1634-1636. 10.1016/S0140-6736(06)69676-1

Gonzalez, J. S., Safren, S. A., Cagliero, E., Wexler, D. J., Delahanty, L., Wittenberg, E., . . Grant, R. W. (2007). Depression, self-care, and medication adherence in type 2 diabetes: Relationships across the full range of symptom severity. Diabetes Care, 30, 2222-2227. 10.2337/dc07-0158 
Gonzalez, J. S., Tanenbaum, M. L., \& Commissariat, P. V. (2016). Psychosocial factors in medication adherence and diabetes self-management: Implications for research and practice. American Psychologist, 71, 539-551. 10.1037/a0040388

Grzywacz, J. G., \& Fuqua, J. (2000). The social ecology of health: Leverage points and linkages. Behavioral Medicine, 26, 101-115. 10.1080/08964280009595758

Interprofessional Education Collaborative Expert Panel. (2011). Core competencies for interprofessional collaborative practice: Report of an expert panel. Washington, DC: Interprofessional Education Collaborative. Retrieved from http://www.aacn.nche.edu/education-resources/ipecreport.pdf

Johnson, S. B. (2013). Increasing psychology’s role in health research and health care. American Psychologist, 68, 311-321.

Kathol, R. G., Butler, M., McAlpine, D. D., \& Kane, R. L. (2010). Barriers to physical and mental condition integrated service delivery. Psychosomatic Medicine, 72, 511-518.

Kelly, J. F. (2014). Proceedings of the American Psychological Association for the legislative year 2013: Minutes of the annual meeting of the Council of Representatives, February 22-24, 2013, Washington, DC, and July 31 and August 2, 2013, Honolulu, HI, and minutes of the February, June, April, July/August, and December 2013 meetings of the Board of Directors. American Psychologist, 69, 483510.

Kirk, S. F., Penney, T. L., \& McHugh, T. L. (2010). Characterizing the obesogenic environment: The state of the evidence with directions for future research. Obesity Reviews, 11, 109-117.

Knowler, W. C., Barrett-Connor, E., Fowler, S. E., Hamman, R. F., Lachin, J. M., Walker, E. A., . . .Diabetes Prevention Program Research Group. (2002). Reduction in the incidence of type 2 diabetes with lifestyle intervention or metformin. The New England Journal of Medicine, 346, 393-403. 10.1056/NEJMoa012512 
Korda, H., \& Eldridge, G. (2011). Payment incentives and integrated care delivery: Levers for health system reform and cost containment. Inquiry: The Journal of Health Care Organization, Provision, and Financing, 48, 277-287.

Leipzig, R. M., Hyer, K., Ek, K., Wallenstein, S., Vezina, M. L., Fairchild, S., . . Howe, J. L. (2002). Attitudes toward working on interdisciplinary healthcare teams: A comparison by discipline. Journal of the American Geriatric Society, 50, 1141-1148.

Lin, E. H., Katon, W., Von Korff, M., Rutter, C., Simon, G. E., Oliver, M., . . Young, B. (2004). Relationship of depression and diabetes self-care, medication adherence, and preventive care. Diabetes Care, 27, 2154-2160.

McDaniel, S., \& DeGruy, F. (2014). Special issue: Primary care and psychology. American Psychologist, 69.

McDaniel, S., Grus, C., Cubic, B., Hunter, C., Kearney, L., Schuman, C., . . Johnson, S. B. (2014). Competencies for psychology practice in primary care. American Psychologist, 69, 409-429.

MedPAC. (2014). Report to the Congress: Medicare payment policy. Retrieved from [http://www.medpac.gov/documents/reports/mar14_entirereport.pdf?sfvrsn=0]

Miniño, A. M., \& Murphy, S. L. (2012). Death in the United States, 2010. NCHS Data Brief, 99, 1-8.

Narayan, K. M., Boyle, J. P., Thompson, T. J., Gregg, E. W., \& Williamson, D. F. (2007). Effect of BMI on lifetime risk for diabetes in the U.S. Diabetes Care, 30, 1562-1566.

Narayan, K. M., Boyle, J. P., Thompson, T. J., Sorensen, S. E., \& Williamson, D. F. (2003). Lifetime risk of diabetes mellitus in the United States. Journal of the American Medical Association, 290, 1884-1890.

National Center for Health Statistics. (2012). Health, United States, 2011: With special feature on socioeconomic status and health. Retrieved from http://www.cdc.gov/nchs/data/hus/hus11.pdf 
O’Donnell, A. N., Williams, M., \& Kilbourne, A. M. (2013). Overcoming roadblocks: Current and emerging reimbursement strategies for integrated mental health services in primary care. Journal of General Internal Medicine, 28, 1667-1672.

Ogden, C. L., Carroll, M. D., Kit, B. K., \& Flegal, K. M. (2014). Prevalence of childhood and adult obesity in the United States, 2011-2012. Journal of the American Medical Association, 311, 806-814. 10.1001/jama.2014.732

O’Rourke, T., \& Iammarino, N. (2002). Future of healthcare reform in the USA: Lessons learned from abroad. Expert Review of Pharmacoeconomics \& Outcomes Research, 2, 279-291. 10.1586/14737167.2.3.279

Pagoto, S., Pbert, L., Emmons, K., \& Society of Behavioral Medicine Public Policy Leadership Group. (2012). The Society of Behavioral Medicine position statement on the CMS decision memo on intensive behavior therapy for obesity. Translational Behavioral Medicine, 2, 381-383. 10.1007/s13142-012-0168$\mathrm{X}$

Patient Protection and Affordable Care Act. (2010). Retrieved from http://www.hhs.gov/healthcare/rights/law/index.html

Pi-Sunyer, X., Blackburn, G., Brancati, F. L., Bray, G. A., Bright, R., Clark, J. M., . . .Look AHEAD Research Group. (2007). Reduction in weight and cardiovascular disease risk factors in individuals with type 2 diabetes: One-year results of the Look AHEAD trial. Diabetes Care, 30, 1374-1383.

10.2337/dc07-0048

Prochaska, J., \& Velicer, W. (1997). The transtheoretical model of health behavior change. American Journal of Health Promotion, 12, 38-48.

Rodriguez-Osorio, C. A., \& Dominguez-Cherit, G. (2008). Medical decision making: Paternalism versus patient-centered (autonomous) care. Current Opinion in Critical Care, 14, 708-713. 
Russell, L. (2013). Biomedicine. In L. Russell, Sociology for health professionals (pp. 6-22). London, UK: Sage. Retrieved from https://us.sagepub.com/sites/default/files/upm-binaries/59005_Russell.pdf

Ruterbusch, J. A. (2014). Prediabetes: The epidemic of the new millennium. Nutritional Perspectives: Journal of the Council on Nutrition, 37, 37-40.

Sallis, J., Owen, N., \& Fisher, E. (2008). Ecological models of health behavior. In K.Glanz, B.Rimer, \& K.Viswanath (Eds), Health behavior and health education: Theory, research and practice (Vol. 4). San Francisco, CA: Jossey-Bass.

Stedman’s medical dictionary (28th ed.). (2006). Baltimore, MD: Lippincott Williams \& Wilkins.

Stice, E. (2002). Risk and maintenance factors for eating pathology: A meta-analytic review. Psychological Bulletin, 128, 825-848.

Stokols, D. (1992). Establishing and maintaining healthy environments: Toward a social ecology of health promotion. American Psychologist, 47, 6-22.

Stokols, D. (1996). Translating social ecological theory into guidelines for community health promotion. American Journal of Health Promotion, 10, 282-298.

Tabák, A. G., Herder, C., Rathmann, W., Brunner, E. J., \& Kivimäki, M. (2012). Prediabetes: A high-risk state for diabetes development. The Lancet, 379, 2279-2290.

Thielke, S., Vannoy, S., \& Unutzer, J. (2007). Integrating mental health and primary care. Primary Care: Clinics in Office Practice, 34, 571-592.

U.S. Preventive Services Task Force. (2014, October). USPSTF A and B recommendations. Retrieved from http://www.uspreventiveservicestaskforce.org/Page/Name/uspstf-a-and-b-recommendations/

Venditti, E. M. (2016). Behavior change to prevent or delay type 2 diabetes: Psychology in action. American Psychologist, 71, 602-613. 10.1037/a0040433 
Weil, T. P. (2015). Insufficient dollars and qualified personnel to meet United States mental health needs. Journal of Nervous and Mental Disease, 203, 233-240.

Wiebe, D. J., Helgeson, V., \& Berg, C. A. (2016). The social context of managing diabetes across the life span. American Psychologist, 71, 526-538. 10.1037/a0040355

Working Party Group on Integrated Behavioral Healthcare. (2014). Joint Principles: Integrating behavioral health care into the patient-centered medical home. Families, Systems, \& Health, 32, 154-156. Young-Hyman, D., \& Peyrot, M. (2012). Psychosocial care for people with diabetes. Alexandria, VA: American Diabetes Association. 


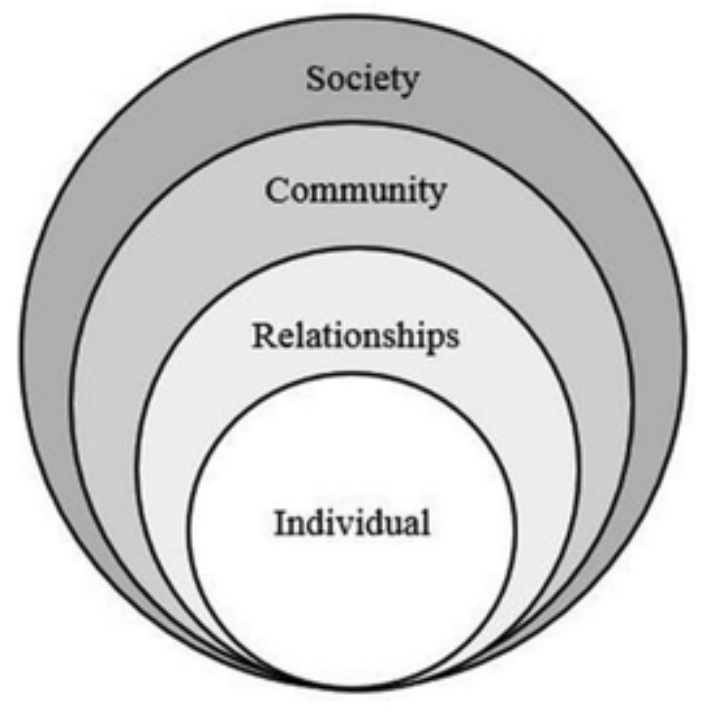

\begin{tabular}{|l|l|}
\hline Individual & $\begin{array}{l}\text { Individual characteristics that } \\
\text { influence behavior, such as } \\
\text { biological, knowledge, attitudes, } \\
\text { beliefs, and perceptions. }\end{array}$ \\
\hline Relationships & $\begin{array}{l}\text { Interpersonal interaction and } \\
\text { primary groups including family, } \\
\text { friends, classmates, co-workers that } \\
\text { provide identity, support and role } \\
\text { designators. }\end{array}$ \\
\hline Community & $\begin{array}{l}\text { Community settings such as health } \\
\text { department, media, non-profit } \\
\text { organizations. Influence of } \\
\text { organization system that include } \\
\text { such groups as schools, workplace, } \\
\text { etc. }\end{array}$ \\
\hline Society & $\begin{array}{l}\text { Social/cultural norms, along with } \\
\text { health, economic and educational } \\
\text { policies along with local, state, and } \\
\text { federal laws. }\end{array}$ \\
\hline
\end{tabular}

